\title{
The Determination of Melanoma Stage at Diagnosis
}

\author{
John A. H. Lee \\ Fred Hutchinson Cancer Research Center, M4-B874, 1100 Fairview Avenue N, Seattle, WA 98109, USA \\ Correspondence should be addressed to John A. H. Lee, jahlee@u.washington.edu
}

Received 15 December 2009; Revised 11 March 2010; Accepted 26 May 2010

Academic Editor: Prashiela Manga

Copyright ( 2010 John A. H. Lee. This is an open access article distributed under the Creative Commons Attribution License, which permits unrestricted use, distribution, and reproduction in any medium, provided the original work is properly cited.

\begin{abstract}
The rising proportion of melanomas diagnosed at an early pathologic stage is commonly ascribed to better public education. However in the US SEER program of cancer registration it has been found that the rates for in situ melanomas are closely related by a log linear relationship to the incidence of invasive melanomas and that this relationship is unrelated to calendar year or gender or patient age. This relationship is sufficiently strong to leave little room for other factors. The relationship may be different in populations with different melanoma rates and responses to them. It is suggested that the results are due to variations within populations of individual response to melanoma cell proliferation.
\end{abstract}

\section{Introduction}

Over recent decades in many prosperous white populations the incidence of malignant melanoma of the skin has been rising. Concomitant with this, there has been a shift towards earlier diagnosis, with a consequent improvement in prognosis. This has been ascribed by numerous authors to improved public and professional education [1-4].

In contrast, it has been shown, in the US populationbased cancer registration system, that there is a systematic proportional relationship between incidence rates for in situ melanoma and invasive melanoma in males and females at all ages and over a long time period [5].

This paper explores the relationship between the incidence rate data for in situ and invasive melanoma further. It shows that the proportionate relationship between the in situ and invasive rates is very powerful and leaves room for only a small contribution by any diagnostic or other historical change. An explanation for the link could be found in variations between individuals in resistance to developing melanomas.

\section{Data and Methods}

The SEER (Statistics Epidemiology and End Results) Program of the U.S. National Cancer Institute (NCI) covers a group of nine geographic areas within the contiguous US that provide population-based cancer registration from 1975 to present. Data from the years 1975 to 2004 for malignant melanoma of the skin were downloaded from the SEER website [6].

This study was restricted to white people. The cases analyzed were restricted to first diagnoses and were all histologically confirmed. Cases were classified at the time of diagnosis as in situ (limited to the epidermis), localized invasive, regional spread, and distant spread. The localized, regional, and distant cases were combined as invasive. The cases unstaged were not analyzed further.

The age range for both males and females was $15-84$ in 14 five-year- age groups.

The association between incidence rate of in situ and of invasive melanoma is modeled by Poisson maximumlikelihood regression. Goodness-of-fit of each model was assessed by a pseudo-R-squared measure that compared a model with just the intercept to a model with intercept and coefficient [7].

The data were tabulated using SEER Stat software [8] and analyzed using Stata 9.0. [9].

\section{Results}

Rates for males and females for single years 1975-2004 and the age range 15-84 are shown for in situ and invasive melanoma for the nine geographic SEER areas combined in 
TABle 1: Parameters of linear models fitted to ln. rates for in situ and invasive melanomas. The parameters are shown for males and females for the entire period (84 data pairs for each gender) and for each period separately (14 data pairs).

\begin{tabular}{lcccccccc}
\hline Gender & Period & Coefficient & ucl & lcl & Constant & ucl & lcl & Pseudo $R^{2}$ \\
\hline Male & $1975-2004$ & 1.700 & 1.722 & 1.677 & -14.891 & -14.806 & -14.977 & 0.940 \\
Female & $1975-2004$ & 2.097 & 2.138 & 2.055 & -15.760 & -15.627 & -15.893 & 0.867 \\
\hline Male & $1975-79$ & 2.275 & 2.607 & 1.944 & -17.358 & -16.415 & -18.300 \\
Male & $1980-84$ & 1.777 & 1.947 & 1.607 & -15.708 & -15.168 & -16.248 \\
Male & $1985-89$ & 1.702 & 1.796 & 1.609 & -15.101 & -14.775 & -15.427 \\
Male & $1990-94$ & 1.594 & 1.659 & 1.529 & -14.537 & -14.298 & -14.777 \\
Male & $1995-99$ & 1.472 & 1.516 & 1.427 & -13.937 & -13.762 & -14.112 & 0.868 \\
Male & $2000-04$ & 1.378 & 1.412 & 1.344 & -13.419 & -13.282 & -13.557 & 0.966 \\
\hline Female & $1975-79$ & 1.766 & 2.186 & 1.347 & -15.750 & -15.627 & -15.893 \\
Female & $1980-84$ & 1.96 & 2.257 & 1.662 & -15.944 & -15.116 & -16.772 \\
Female & $1985-89$ & 1.733 & 1.914 & 1.552 & -14.905 & -14.375 & -15.434 \\
Female & $1990-94$ & 1.613 & 1.734 & 1.491 & -14.247 & -13.882 & -14.613 & 0.986 \\
Female & $1995-99$ & 1.542 & 1.631 & 1.453 & -13.880 & -13.592 & -14.168 \\
Female & $2000-04$ & 1.492 & 1.563 & 1.421 & -13.571 & -13.332 & -13.809 & 0.783 \\
\hline
\end{tabular}

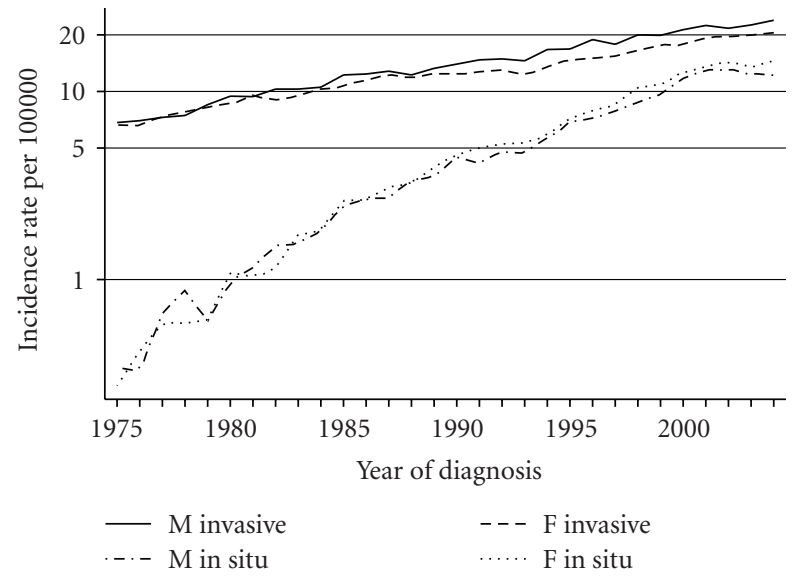

Figure 1: Rates at the time of diagnosis for invasive and in situ melanoma by single calendar years, US SEER program.

Figure 1. The rates are similar in males and females, while, as expected, over time the in situ rates rise much faster than the invasive.

In Table 1 log linear models are shown for males and females relating the in situ and invasive rates for all discrete populations, defined by gender, age from 15 to 84 and period, from 1975-79 to 2000-2004. The confidence limits are very close and the coefficients of variation are close to one.

The models and rates are shown in Figure 2.

Similar models are also shown in the table for the separate 5-year time periods from 1975-1979 to 2000-2004. The coefficients decline slowly, apparently as the in situ rates approach a maximum (Figure 1). The coefficients of the period specific models for each sex are highly unlikely to be due to chance.

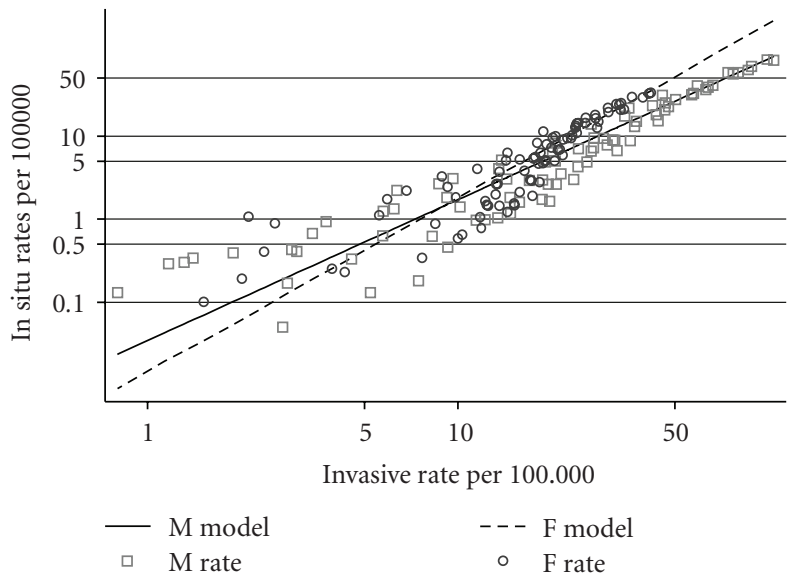

FIgure 2: In situ rates at diagnosis plotted against invasive rates at diagnosis for six five-year-time periods (1975-2004) and fourteen five year age groups (15-190-80-84), and linear models (Table 1) (Males and Females, SEER [6]).

Figure 3 shows the set of 84 observed rates for in situ melanoma and estimated rates derived from the single two-parameter log linear equation and the set of observed invasive rates for males. The picture for females is similar. This is a demonstration (not a test, as there is only one data set) of the power of the relationship and its indifference to time or age.

\section{Discussion}

The connection between log incidence and log invasive rate for malignant melanoma is a substantial feature of the disease. The real distinction maybe between the tumors that have failed to penetrate into the dermis and those that 


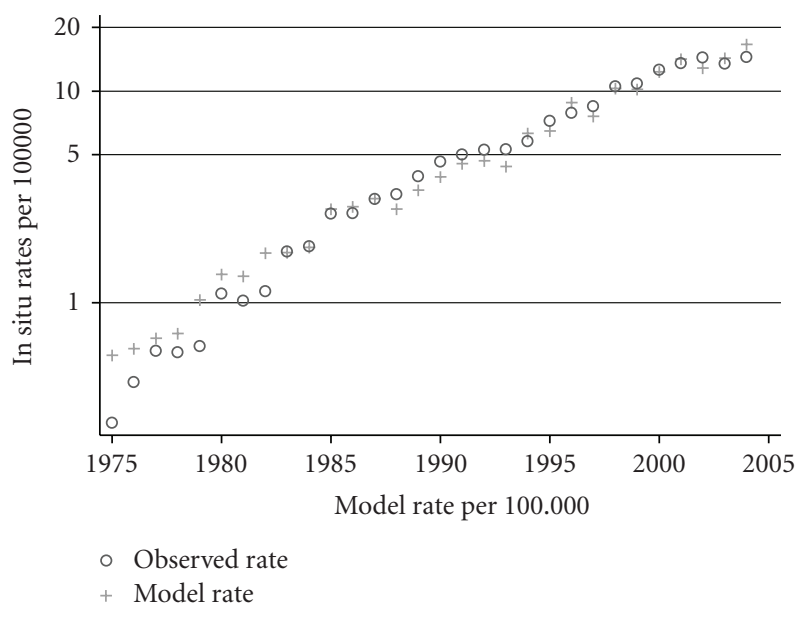

Figure 3: Comparison between observed rates in males for in situ melanoma and model rates derived from the single log linear equation for the whole period (Table 1) giving in situ rates derived from invasive rates for single years 1975-2004.

have. But the precise value of the relationship may be an artifact produced by the original choice invasive rates as the independent variable and in situ rates as the dependent. For instance, a cutting point within the scale of Breslow thickness might be even better.

It is probable that resistance to the multiplication of malignant melanoma cells varies between people, and the systematic relationship between in situ and invasive rates reflects this. In a benign environment, those with the poorest resistance will be the only ones to get a melanoma and will present with the most advanced disease; in a severe environment, stronger resistors will get the disease, but be able to keep it in situ.

The data reported here are combined from nine SEER geographic populations scattered the United States from Detroit to Hawaii. Their separate examination could be helpful. It is possible that in other populations, such as those of Australia and New Zealand with different melanoma rates and different responses, other relationships will be found.

\section{References}

[1] E. Månsson-Brahme, H. Johansson, O. Larsson, L. E. Rutqvist, and U. Ringborg, "Trends in incidence of cutaneous malignant melanoma in a Swedish population 1976-1994," Acta Oncologica, vol. 41, no. 2, pp. 138-146, 2002.

[2] M. Coory, P. Baade, J. Aitken, M. Smithers, G. R. C. McLeod, and I. Ring, "Trends for in situ and invasive melanoma in Queensland, Australia, 1982-2002," Cancer Causes and Control, vol. 17, no. 1, pp. 21-27, 2006.

[3] A. Downing, J. A. Newton-Bishop, and D. Forman, "Recent trends in cutaneous malignant melanoma in the Yorkshire region of England; incidence, mortality and survival in relation to stage of disease, 1993-2003," British Journal of Cancer, vol. 95, no. 1, pp. 91-95, 2006.

[4] B. Peric, J. Zgajnar, N. Besic, and M. Hocevar, "Changing biology of cutaneous melanoma," Melanoma Research, vol. 18, no. 3, pp. 225-229, 2008.
[5] J. A. H. Lee, "The systematic relationship between melanomas diagnosed in situ and when invasive," Melanoma Research, vol. 11, no. 5, pp. 523-529, 2001.

[6] Surveillance, Epidemiology, and End Results (SEER) Program, "SEER* Stat Database: Incidence-SEER 9 Regs Limited-Use, Nov 2006 Sub (1973-2004), National Cancer Institute, DCCPS, Surveillance Research Program, Cancer Statistics Branch, released April 2007, based on the November 2006 submission," http://www.seer.cancer.gov/.

[7] J. S. Long and J. Freese, "Scalar measures of fit for regression models," Stata Technical Bulletin, vol. 10, no. 56, pp. 34-41, 2001.

[8] Surveillance Research Program, National Cancer Institute, "SEER stat software version 6.4.4".

[9] Stata Corporation, Stata Statistical Software, Release 9, Stata Corporation, College Station, Tex, USA, 2005. 


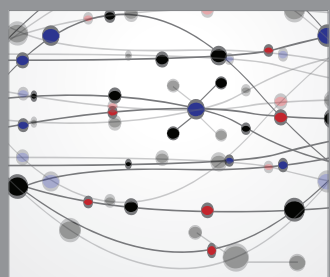

The Scientific World Journal
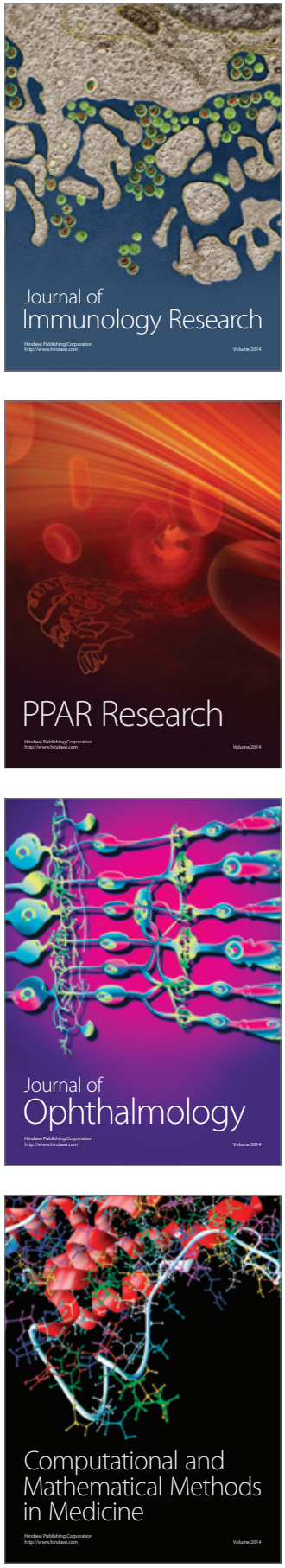

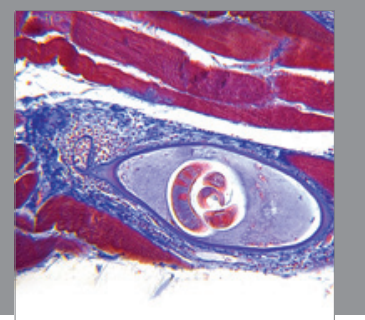

Gastroenterology

Research and Practice
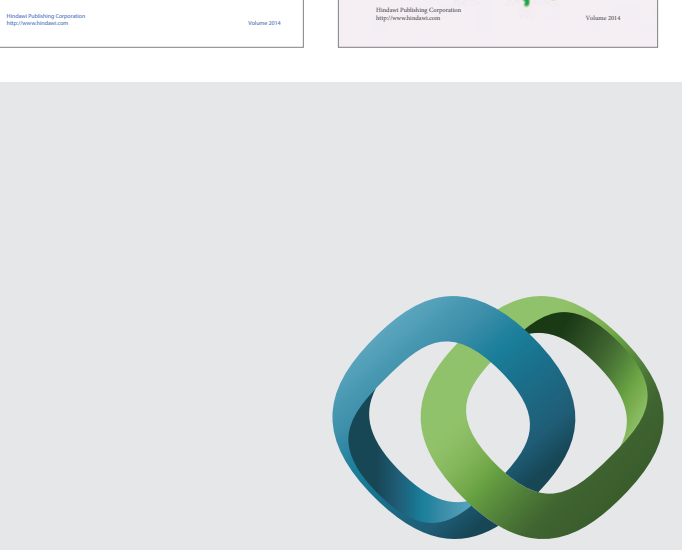

\section{Hindawi}

Submit your manuscripts at

http://www.hindawi.com
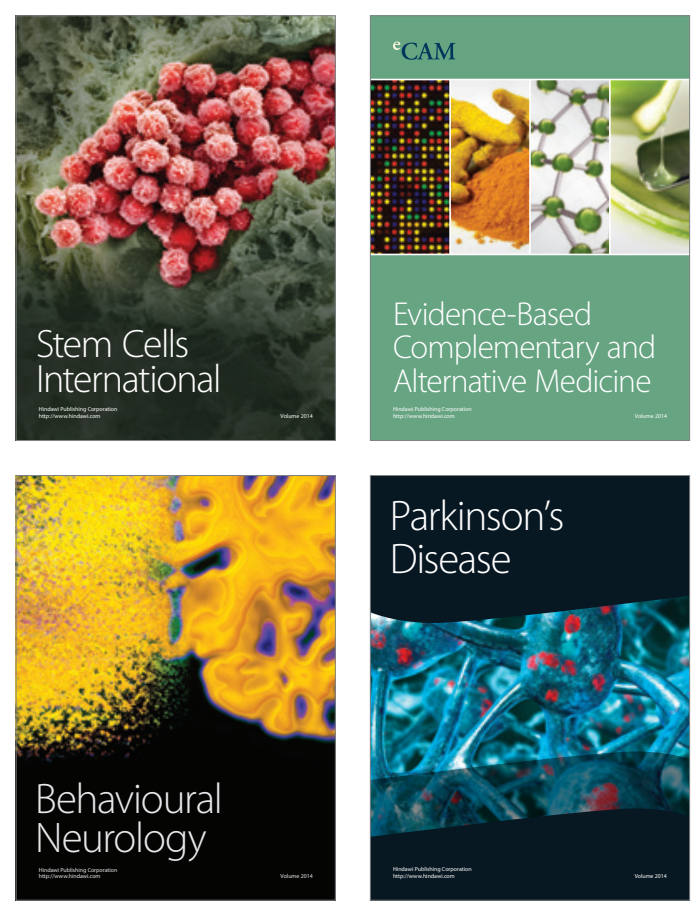

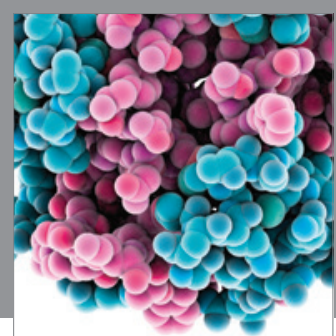

Journal of
Diabetes Research

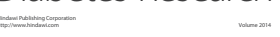

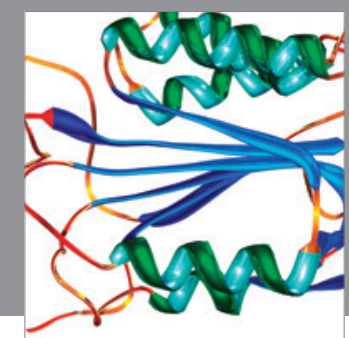

Disease Markers
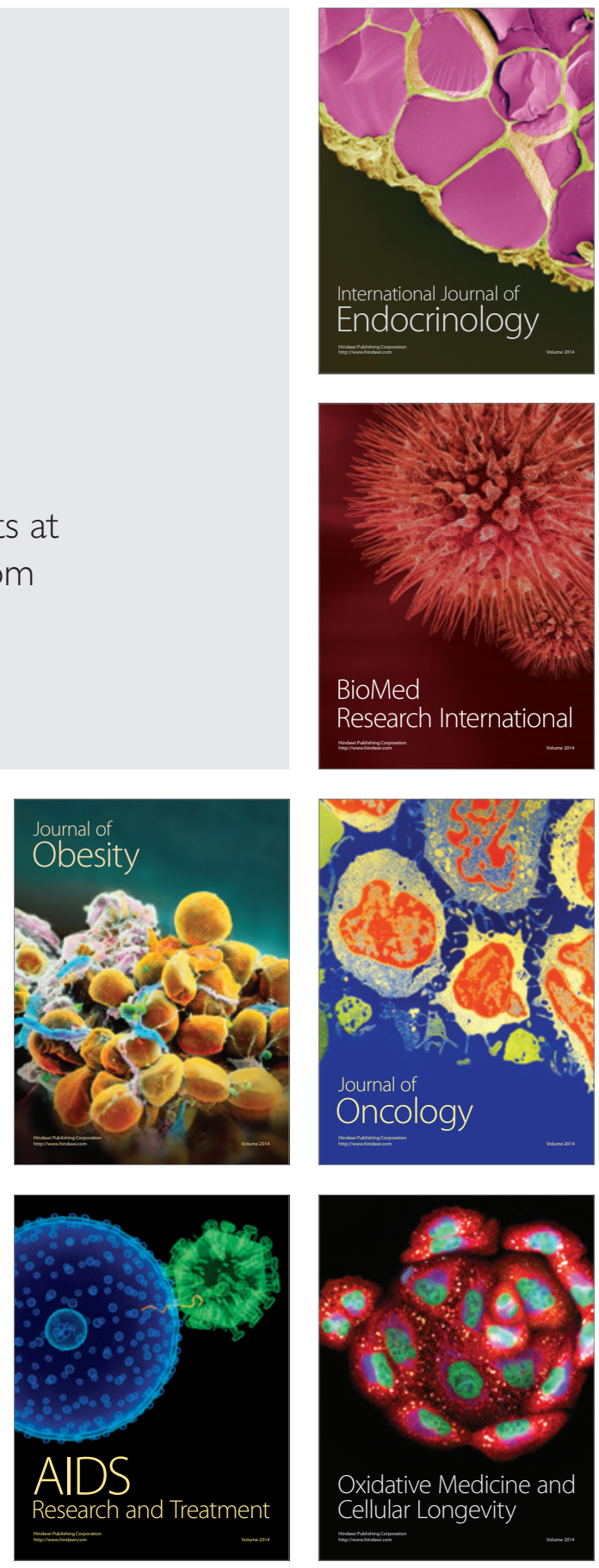